\title{
Р. Р. Муслумов
}

\section{Проблемы формирования правового самосознания личности}

Актуальность рассматриваемой проблемы определяется наличием противоречия между социальными условиями, предъявляющими особые требования к формированию правового самосознания личности и недостаточной изученностью психолого-педагогических факторов и механизмов его развития, а также слабой разработанностью теоретико-методологических аспектов проблемы. Методологической основой теоретического исследования явился системно-структурный подход; применялись общенаучные методы анализа и синтеза, индукции и дедукции, единства исторического и логического; объект рассматривался на стыке психологии и права. Результаты исследования показали, что правовое самосознание личности выступает одновременно как процесс и как результат выработки личностью относительно устойчивой осознанной системы представлений о самой себе в правовом пространстве, осознание себя субъектом права, своей роли, целей, интересов, ценностных ориентаций, идеалов и мотивов правового поведения. Это выделение себя, отношение к себе, оценка своих возможностей в правовых отношениях, которые являются необходимым компонентом правового сознания как целого. В зависимости от субъекта правовое самосознание может выступать в форме индивидуального и в форме социального самосознания (больших и малых социальных групп). Правовое самосознание не имеет самостоятельного пути развития отдельного от развития личности. Правовое самосознание - динамичное, исторически развивающееся образование, выступающее на разных уровнях и в разных формах, является сложным структурным образованием. Правовое самосознание личности включает три основных компонента: когнитивный, эмоционально-оценочный (самоотношение), поведенческий. Каждый из рассмотренных компонентов в свою очередь имеет сложную структуру, отражающую разнообразные процессы, модальности «я», механизмы правового самосознания. Происхождение деформаций правового самосознания личности объясняется нарушениями в его структуре и функциях. Определены новые направления в исследовании феномена правового самосознания личности, среди которых явления травли и кибертравли, харассмента, правовой активности, криминальных и асоциальных субкультур, правовое самосознание представителей лгБТ, экологическое сознание.

Ключевые слова: самосознание, образ Я, Я-концепция, структура правового самосознания, компоненты, самооценка, развитие самосознания, деформации правового самосознания, саморазвитие, саморегуляция, самоконтроль, защитные механизмы

\section{Ссылка для цитирования:}

Муслумов Р. Р. Проблемы формирования правового самосознания личности // Перспективы науки и образования. 2019. № 6 (42). C. 44-54. doi: 10.32744/pse.2019.6.4 


\section{R. R. MusLumov}

\section{Issues of formation of legal consciousness of personality}

The relevance of this issue is a contradiction between the social conditions requiring special requirements for the formation of legal consciousness of a person and insufficient knowledge of psychological and pedagogical factors and mechanisms of its development, weak development of theoretical and methodological aspects of the problem. The methodological basis of the theoretical research was the system-structural approach; general scientific methods of analysis and synthesis, induction and deduction, unity of historical and logical were applied; the object was considered at the interface of psychology and law. The results of the study showed that the legal consciousness of the person acts both as the process and as the result of the development by the individual of a relatively stable conscious system of representations about himself in the legal space, consciousness as a subject of law, roles, goals, interests, value orientations, ideals and motives of legal behavior. It is the identification of oneself, attitude and the assessment of the possibilities in legal relations, which are a necessary component of legal consciousness as a whole. Legal consciousness can act in the form of individual and in the form of social consciousness depending on the subject (large and small social groups). Legal consciousness does not have an independent path of development separate from the development of the individual. Legal identity - a dynamic, historically developing education, acting at different levels and in different forms, is a complex structural entity. Legal consciousness of a person includes three main components: cognitive, emotionallyevaluative (self-attitude), and behavioral. Each of the considered components, in turn, has a complex structure that reflects a variety of processes, modalities of "I", and mechanisms of legal consciousness. The origin of deformations of a person's legal consciousness is explained by violations in its structure and functions. New directions have been identified in the study of the phenomenon of legal consciousness of the person, including the phenomena of bullying and cyberbullying, harassment, legal activity, criminal and antisocial subcultures, legal consciousness of LGBT persons and ecological consciousness.

Key words: consciousness, self-identity, one's self-concept, structure of legal consciousness, components, self-assessment, development of consciousness, deformation of legal consciousness, self-development, self-regulation, self-control, defense mechanism

\section{For Reference:}

Muslumov, R. R. (2019). Issues of formation of legal consciousness of personality. Perspektivy nauki $i$ obrazovania - Perspectives of Science and Education, 42 (6), 44-54. doi: 10.32744/pse.2019.6.4 
овременный человек должен быть эффективен в том, что он делает, успешно вступать во взаимодействие, включаться в многочисленные общественные и организационные системы. Выстраивание коммуникации, видение своих возможностей, способность применить себя требует от индивида знания и исполнения собственных прав и обязанностей. Проблема развития правового самосознания личности является одной из центральных в процессе демократизации, становления правового государства и гражданского общества, что приводит к необходимости исследования правосознания в свете психолого-педагогических аспектов его формирования. Правовое самосознание является важнейшей внутренней предпосылкой поведения человека в различных сферах общественных отношений, которые регулируются нормами права. Проблема носит междисциплинарный характер, и несмотря на большое количество работ, посвященных изучению самосознания личности, и сегодня не разработана концепция правового самосознания, не получили должного психологического обоснования теория, методология, методы и система практических мер по развитию правового самосознания личности в условиях нестабильного трансформирующегося общества.

Важнейшим источником преобразований в сфере права является не только непосредственно законодатель, но и опосредовано изменяющееся общественное мнение, которое через «петлю обратной связи» воздействует на общество и его нормы [1, с. 33-40]. Согласно «петле Фридмана», отражаясь в общественном мнении, закон изменяется, находит определенное русло в своем воплощении, так решается задача согласованности правовой идеологии и правовой психологии.

Правовое самосознание тесно связано с феноменом самосознания личности, сущность и вопросы формирования которого как основы человеческой субъективности, рассматривались уже в античной философии Сократом, Платоном, Аристотелем, Плотином, в средние века эта проблема анализируется Августином Блаженным, Фомой Аквинским, в эпоху Возрождения и в Новое время Н. Кузанским, Р. Декартом, Ф. Бэконом, Б. Спинозой, Дж. Локком, Г. В. Лейбницем, Г. Гегелем, И. Кантом и др. [2]. В современной психологии среди зарубежных ученых самосознание и способы его формирования изучали А. Адлер, У. Джемс, Р. Бернс, Ч. Кули, Дж. Мид, А. Маслоу, Р. Кеттел, К. Роджерс, Г. Олпорт, К. Хорни, К. Юнг, Э. Эриксон, Э. Фромм, З. Фрейд и многие другие. В отечественной психологии проблема самосознания анализируется в работах Б. Г. Ананьева, Л. И. Божович, А. Н. Леонтьева, С. Л. Рубинштейн, И. С. Кона, К. А. Абульхановой, Т. Н. Березиной, Ф. Е. Василюк, Д. И. Фельдштейна, В. А. Ядова и др. Немало работ посвящено изучению профессионального и этнического самосознания.

Большой вклад в изучение сущности и социальной роли правосознания внесли представители классической немецкой философии И. Кант и Г. Гегель. Основные принципы и максимы правосознания в отечественной науке анализировали И. А. Ильин, Н. А. Бердяев, В. С. Соловьев, Г. Ф. Шершеневич. Проблемы формирования правосознания разрабатывали С. С. Алексеев, Р. С. Байниязов, Л. С. Мамут, Д. Э. Марченко, Н. И. Матузов, Ф. Ш. Ямбушев и др. Правовое поведение исследовали М. В. Бондаренко, Е. А. Ковалев, В. Я. Кудрявцев, М. Ф. Орзих, И. В. Тенляшин, Н. В. Щербакова, В. М. Шафиров и многие другие. 
Эти многочисленные труды не потеряли своей значимости и сегодня, одни из них имеют фундаментальное значение, другие вызывают дискуссию. В связи с проблемой реализации закона правосознание является одним из наиболее важных и широко изучаемых во всем мире, в исследовании вопросов формирования которого в последние годы наблюдается все большая активность. Так, согласно Чуа и Энгел количество публикаций по проблеме правосознания возросло более чем в пять раз за последние четверть века [3]. Обзор научной литературы показывает, что правосознание рассматривается преимущество как форма общественного сознания, как целостное явление, а изучение правового самосознания личности как важнейшего его компонента не получило должного внимания, в то же время теория и практика данной проблемы требует более предметного и обстоятельного подхода.

Задачей нашей статьи является проведение теоретического анализа проблемы правового самосознания личности, определение его сущности, выделение и характеристика его структурных компонентов, определение перспективных областей прикладных исследований в этом направлении.

Материалы и методы

Вопросы формирования и развития правового самосознания невозможно решить, не опираясь на исследования сущности сознания, самосознания и правового сознания. Правовое самосознание имеет те же гносеологические корни, что и сознание, т. е. отражательную природу. Объектом самосознания является сама личность, ее мысли, чувства, потребности, весь ее внутренний мир. Методологической основой нашего исследования правового самосознания личности и совокупности факторов, его обусловливающих явился системно-структурный подход; применялись общенаучные методы анализа и синтеза, индукции и дедукции, единства исторического и логического, моделирования. Рассматривая явления на стыке психологии и права, обратились к сравнительному методу исследования для оценки понятий «самосознание», «правовое сознание» и «правовое самосознание».

\section{Результаты исследования}

Самосознание является условием личностной самоидентификации и самоопределения. А. Г. Спиркин определяет понятие «самосознание» как «осознание и оценку человеком своих действий и их результатов, мыслей, чувств, морального облика и интересов, идеалов и мотивов поведения, как целостную оценку самого себя и своего места в жизни. Самосознание - конституирующий признак личности, формирующийся вместе со становлением последней» [4, с. 149]. Самосознание предполагает выделение субъектом самого себя в качестве носителя определенной активной позиции по отношению к окружающему миру. Выделение себя, отношение к себе, оценка своих возможностей характеризуют важнейшие качества личности. Представители разных научных школ и направлений считают, что структура самосознания закладывается в детском возрасте, наиболее ярко и наглядно формирование самосознания происходит в подростковом и раннем юношеском возрасте.

Правовое сознание возникает на определенном историческом этапе, оно обусловлено возникновением государства и права. Типы правового сознания определяются 
соответствующими общественно-экономическими формациями и политическими режимами. Общественная обусловленность формирования правового сознания отражается в законах общества, в правовых отношениях, в понимании личностью правовых норм. Правовое сознание представляет собой систему знаний, оценок, настроений и чувств, выражающих отношение к праву, действующему законодательству и юридической практике.

Правовое самосознание как важнейшая сторона правосознания предполагает выделение субъектом самого себя в качестве носителя определенной активной позиции по отношению к праву, к правовым отношениям. Правовое самосознание личности мы рассматриваем как процесс и одновременно как результат выработки ею относительно устойчивой осознанной системы представлений о самой себе в правовом пространстве, осознание себя субъектом права, своей роли, целей, интересов, ценностных ориентаций, идеалов и мотивов правового поведения. Это выделение себя, отношение к себе, оценка своих возможностей, которые являются необходимым компонентом правового сознания как целого. В акте правового самосознания сознание человека, будучи субъективной формой действительности, само раздваивается на субъект и объект, на сознание, которое познает, и сознание, которое познается.

В зависимости от субъекта правовое самосознание может выступать в форме индивидуального и в форме социального самосознания (больших и малых социальных групп). Определенную сложность представляет изучение индивидуального самосознания, в котором наблюдается раздвоение сознания личности на объект и субъект. Самосознание не имеет самостоятельного пути развития отдельного от развития личности. Согласно С. Л. Рубинштейну, самосознание - это «осознание самого себя как сознательного субъекта, реального индивида, а совсем не осознание своего сознания». Подлинным источником и движущими силами развития самосознания выступают «растущая самостоятельность индивида, его деятельность и взаимоотношения с окружающими» [5].

Современная ситуация социального развития характеризуется тем, что человеку приходится не просто включаться в систему устоявшихся правил и норм, но и принимать самостоятельные решения, которые не нашли отражения в социальных нормах. Постоянно появляются новые виды и формы поведения, с квалификацией которых возникают сложности даже у профессиональных юристов, не говоря уже о трудностях такой квалификации у простых граждан, как например, использование биткоинов, кибертравля, авторское право в интернет и прочее. Одновременно с этим наблюдается огромный информационный поток суждений, решений, мнений, который создает ощущение правового и нравственного хаоса.

Становление правового самосознания начинается с чувственного и рационального познания окружающего мира, оценки социальной обстановки, усвоения содержания права и юридической практики, рефлексии сознания. Формирование правового самосознания личности осуществляется в процессе правовой социализации, включающей в себя перевод внешнего нормативного воздействия во внутренний мир человека, создания внутренней нормативной системы. В процессе социализации правовые нормы усваиваются индивидом и становятся личностными, «внутренними» регуляторами повеления. «При этом усвоенные человеком нормы воздействуют на его поведение через систему других внутренних факторов - например, через Я-концепцию индивида, посредством социальных установок и т. д. Механизм нормативной саморегуляции поведения зависит от степени осознания и принятия тех или иных норм личностью. 
Осознанные нормы выступают в качестве эталонов, с которыми индивид соотносит свои и чужие поступки, регулируя тем самым свое поведение» [6, с. 211].

В развитии правового самосознания можно выделить два уровня: обыденный и теоретический. Обыденный уровень опирается на будничные взаимоотношения между людьми, на обычаи, традиции, стереотипы, слухи и пр. Теоретический уровень основывается на правовых понятиях, знании законов, правовой идеологии, помогающих осмыслить суть правовых проблем. Здесь идет осмысление таких структурных компонентов как правовые ценности, смыслы и идеалы, правовое мировоззрение, которые связывают правовое самосознание с правовым поведением человека.

Самосознание - динамичное, исторически развивающееся образование, выступающее на разных уровнях и в разных формах. Самосознание является сложным структурным образованием. Г. М. Андреева, рассматривая самосознание как сложный психологический процесс, выделяет следующие компоненты: самоопределение (поиск позиции в жизни), самореализацию (активность в разных сферах), самоутверждение (достижение, удовлетворенность), самооценку. При этом самосознание предстает не как простой перечень составляющих его компонентов, а как некая целостность, личностная идентичность [7], что имеет особое значение в области педагогических практик, направленных на формирование правового самосознания.

Самый высокий уровень развития самосознания - это возникновение «Я-концепции». Понятие «Я-концепции» было введено в науку У. Томасом и Ф. Знанецким в 1918 г. Первым из психологов начал разработку проблематики Я-концепции У. Джемс, который анализирует личностное «Я» как двойственное образование, объединяющее Я-сознающее (процесс познания самого себя, чистый опыт) и Я-как объект (содержание опыта) [8, с. 80]. Р. Бернс определяет Я-концепцию как «совокупность всех представлений индивида о себе, сопряженную с их оценкой» [9]. «С точки зрения психологии, - пишет А. Г. Спиркин, - человеческое «Я»- это высшее и сложнейшее интегральное образование в духовном мире человека, это динамическая система всех сознательно осуществляющихся психических процессов. «Я»-и сознание, и самосознание как целое. Это некий нравственно-психологический, характерологический и мировоззренческий стержень личности» [10]. Я-концепция состоит из взаимосвязанных подструктур или относительно устойчивых «Я-образов» («актуальное Я», «реальное Я», «идеальное Я» и т. п.).

В большинстве работ отечественной психологии выделяют следующие структурные компоненты самосознания: когнитивный (Я-образы); эмоционально-оценочный (самоотношение); поведенческий (регулятивный).

Правовое самосознание как определенная форма также структурно организовано, представляет собой целостную систему, состоящую из различных элементов, находящихся между собой в закономерных отношениях. Структура правового самосознания личности - это совокупность взаимосвязанных и взаимодействующих компонентов, обеспечивающих целостность правового самосознания, его развитие и функционирование.

Правовое самосознание включает три основных компонента:

- Когнитивный компонент выступает как образ я, как представление индивида о себе, «самоописание» через тот или иной набор отдельных черт, ролевые, атрибутивные или статусные характеристики. Индивид имеет множество образов (семьянин, гражданин, студент). Многие из этих образов определены законодательством, наделены соответствующими правами и обязанностями. 
Когнитивный компонент правового самосознания характеризует уровень правовых знаний, умений, навыков личности, позволяющий определить границы, возможности и способности в правовом поле при исполнении различных ролей. Он проявляется также в отношении к правам других лиц.

- Эмоционально-оценочный (самоотношение) компонент включает общее чувство «за» или «против» себя, так и такие измерения как самоуважение, аутосимпатию, самоинтерес, уверенность в себе, удовлетворенность собой, чувство собственного достоинства, принятие себя. Важнейшей составляющей является самооценка как ценность, значимостью которой индивид наделяет себя в целом и отдельные стороны своей личности, деятельности, поведения. Основу самооценки составляет система личностных смыслов индивида, принятая им система ценностей. Самооценку делят на адекватную, заниженную и завышенную. Люди с различными типами самооценки в одинаковых ситуациях могут вести себя совершенно по-разному. Эмоциональный аспект правового самосознания характеризует правовые эмоции и чувства индивида, он выражается в степени одобрения требований правовых норм, в определенном субъективном отношении к знанию своего правового статуса, который может восприниматься как благоприятный или неблагоприятный, высокий или низкий, устраивать или не устраивать.

- Поведенческий компонент - это поведенческие установки, конкретные действия, вызванные образом Я и самоотношением, которые проявляются в саморегулировании, самоконтроле, самоактуализации, самовоспитании и пр. Между реальным поведением и Я - концепцией нередко возникает рассогласованность. Механизмы психологической самозащиты делают это рассогласование более терпимым. Защитные механизмы могут обнаруживаться в любом поведении. Впервые защитные механизмы были выявлены еще 3. Фрейдом, однако и на сегодняшний день в правовом поведении они не получили должного изучения.

Каждый из рассмотренных компонентов в свою очередь имеет сложную структуру, отражающую разнообразные процессы, модальности «Я», механизмы правового самосознания. В своей совокупности рассмотренные компоненты правового самосознания образуют целостный образ самого себя в праве, существующий на разных уровнях развития. Уровень развития правового самосознания различен как у разных людей, так и на различных этапах жизненного пути одного человека.

Формирование правового самосознания личности предполагает, что человек воспринимает нормы права не только как инструмент реализации своих желаний и находится в курсе обязанностей, подлежащих исполнению, но и осознанно рассматривает правовые нормы как точку отсчета своей личности. Это связано с интеграций самооценки и правовой оценки своего поведения. Цели и ценности человека согласованы и выступают единым смысловым комплексом, а оценка явлений окружающей жизни преломляется через представление о правовой норме.

Деформации правового самосознания связаны с нарушениями в формировании отдельных компонентов и уровней правового самосознания личности. Так, например, правовой нигилизм, можно рассмотреть не просто как наличие негативной эмоциональной оценки права и сформированных отрицательных правовых установок, на фоне иногда значительных правовых знаний, но и как личностную деформацию, нарушение смысловой структуры права, устойчивую эгоистическую позицию в обществен- 
ных отношениях, искажение мотивации правового поведения. Деформация правового самосознания проявляются в различных формах: правовой инфантилизм, правовой негативизм, правовой нигилизм, правовой релятивизм, правовой идеализм, правовой фетишизм, правовой субъективизм, криминальное самосознание.

\section{Обсуждение результатов}

Правовое самосознание не имеет своей отдельной от личности линии развития, оно включается как сторона в процесс ее реального развития. По мере того, как человек приобретает жизненный опыт перед ним не только открываются новые стороны бытия, но и происходит переосмысление жизни, формируются интересы, ценностные ориентации, определяются мотивы поведения и внутренний смысл тех задач, которые он разрешает в жизни. В формировании правового самосознания значение имеет не только внешняя среда, но и внутренние условия, взаимозависимость когнитивного и личностного развития личности. Основные компоненты правового самосознания тесно взаимосвязаны, однако они возникают в онтогенезе не одновременно и могут существенно отличаться по уровню своего развития. Исследования в области правового самосознания дают возможность оценить прикладные проблемы правоприменения в рамках психологии, открывают перспективу использования данных в различных областях психологического знания и на стыке педагогики, психологии с другими науками. Актуальными педагогическими и психологическими прикладными проблемами в данном направлении, на наш взгляд, являются:

- Буллинг и кибербуллинг, как явления не новые, но значительно обострившиеся в связи со снижением способности молодежи к решению межличностных конфликтов и выстраиванию взаимодействия с окружающими [11].

- Харассмент, в узком смысле, как проблема сексуального домогательства, а в широком, как оскорбление другого человека по какому-либо стигматизирующему признаку (пол, национальность, сексуальная ориентация и пр.) Анализ восприятия правовой нормы, как средства защиты и реальной практики применения права позволил бы изучить почему потенциальная жертва обращается или отказывается от обращения за справедливостью, по аналогии с исследованием Бойтина [12].

- Правовая активность, как декларируемая необходимость уметь отстаивать свои законные права, но при этом незнание конкретных алгоритмов решения своих проблем. В связи с этим появляются такие сообщества как «Стопхам», «Лев против» и другие, где члены самостоятельно решают проблемы аморального и противозаконного поведения.

- Проблема преподавания правоведения для будущих неспециалистов права (педагогов, управленцев и пр.).

- Многочисленные деформации правосознания, проявляющиеся в поведении, в негативной оценке институтов права и их представителей, осуждении лиц, живущих по закону.

- Проблема криминальной и асоциальной субкультур, а также проблемы субкультур, вступающих в противоречие с правовой культурой, но являющиеся при этом средствами социализации и идентификации. Такими, например, выступают фанатские сообщества. 
- Правовое самосознание представителей лгБт сообществ, в контексте восприятия изменений Кодекса Российской Федерации об административных правонарушениях федеральным законом от 29.06.2013 № 135-Ф3 «о запрете пропаганды нетрадиционных сексуальных отношений среди несовершеннолетних» [13]. Такое направление может быть интересно и в контексте практики изучения данных вопросов за рубежом, как в исследованиях Ричмана [14] или Хардинга [15].

- Возрастающий интерес к экологическим вопросам, где зачастую активные граждане, ориентированные на решение экологических проблем, идут впереди государственных структур, призванных заниматься решением этих вопросов [16].

Правовое самосознание личности оказывает влияние на все стороны жизни, и это вызывает необходимость изучения его механизмов, закономерностей формирования, функционирования и развития, разработки способов оптимизации и коррекции [17; 18], а также особенностей его функционирования в условия конфликта [19; 20]. Особого внимания требует создание психолого-педагогических условий, способствующих развитию правового самосознания молодежи.

Заключение

Выделено новое в контексте психологических исследований понятие - «правовое самосознание», предоставляющее перспективы анализа целой группы явлений на стыке психологии и права. Раскрыта сущность правового самосознания личности, представлена структура этого явления, включающего когнитивный, эмоциональнооценочный и поведенческий компоненты, обозначены уровневые критерии оценки каждого из них. Обосновывается предположение о происхождении деформаций правового самосознания в связи с нарушением согласованности указанных компонентов. Основываясь на изложенных теоретических положениях, перечислены актуальные прикладные проблемы, требующие своего разрешения.

\section{ЛИТЕРАТУРА}

1. Friedman L. M. The concept of legal culture: a reply. In: Comparing; Legal Cultures. Dartmouth Publishing Company, Brookfield, VT, 1997. P. 33-40.

2. Гарнцев М. А. Проблема самосознания в западноевропейской философии (от Аристотеля до Декарта). М., 1987. 215 c.

3. Chua L. J., Engel D. M. Legal Consciousness Reconsidered // Annual Review of Law and Social Science 2019, vol. 15:1, рр. 335-353

4. Спиркин А. Г. Сознание и самосознание. М.: Изд-во политической литературы, 1972. 304 с.

5. Рубинштейн С. Л. Основы общей психологии. СПб.: Изд-во Питер. 2008. 713 с.

6. Белинская Е. П., Тихомандрицкая О. А. Социальная психология личности: Учеб. пособие для вузов. М.: Аспект Пресс, 2001. 238 с.

7. Андреева Г. М. Социальная психология. М.: Аспект Пресс, 2009. 432 с.

8. Джемс У. Д. Психология. М.: Педагогика, 1991. 368 с.

9. Бернс Р. Развитие Я-концепции и воспитание. М., 2016. 420 с.

10. Спиркин А. Г. Сознание и самосознание. М.: Изд-во политической литературы, 1972. 304 с.

11. Фельдштейн Д. И. Глубинные изменения современного детства и обусловленная ими актуализация психолого-педагогических проблем развития образования [Электронный ресурc]. URL: http://psyjournals.ru/ vestnik_psyobr/2011/n4/56243.shtml (дата обращения: 05.09.2019).

12. Boittin M. L. 2013. New perspectives from the oldest profession: abuse and the legal consciousness of sex workers in China. Law Soc. Rev. 47(2):245-278. doi: 10.1111/lasr.12016 
13. Кодекс Российской Федерации об административных правонарушениях от 30.12.2001 № 195-Ф3 (ред. от 02.08.2019).

14. Richman K. D. License to Wed: What Legal Marriage Means to Same-Sex Couples. New York/London: NYU Press. 2014.

15. Harding R. Regulating Sexuality: Legal Consciousness in Lesbian and Gay Lives. London: Routledge. 2011.

16. Благодатских В. Г., Керимов А. А. Образование в структуре формирования экологической культуры общества // ДИСКУРС-ПИ. 2018. № 18. 1(30). С. 40-46

17. Kerimov A., Shutaleva A. Education as a factor in preventing ethnic conflicts in modern Russia // INTED2017: 11th international technology, education and development conference. Chova L. G., Martinez A. L. \& Torres I. C. (ред.). International Academy of Technology, Education and Development, 2017. C. 1382-1391.

18. Kerimov A. A. The parliamentary system in modern Russia: peculiarities and problems of implementation // Вестник Томского государственного университета. Философия. Социология. Политология. 2019. № 48. С. 145-153.

19. Rudenkin D., Loginov A. Ideologiya v obshchestve pozdnego moderna: ischeznovenie ili transformatsiya? [Ideology in Late Modern Society: Disappearance or Transformation?]. The Russian Sociological Review, 2018, vol. 17, no 3, pp. 197-220 (in Russian)

20. Menshikov A.S. Antropologiia bez etnografii: filosofiia voiny M. Shelera i poisk "prirody cheloveka" [Anthropology without Ethnography: M. Scheler's Philosophy of War and the Search for the "Nature of Man"]. Etnograficheskoe obozrenie, 2018, no. 5, pp. 43-58. https://doi.org/10.31857/S086954150001476-3

\section{REFERENCES}

1. Friedman L. M. The concept of legal culture: a reply. In: Comparing; Legal Cultures. Dartmouth Publishing Company, Brookfield, VT, 1997. pp. 33-40.

2. Garntsev M.A. The problem of self-consciousness in Western European philosophy (from Aristotle to Descartes). Moscow, 1987. 215 p.

3. Chua L. J., Engel D. M. Legal Consciousness Reconsidered. Annual Review of Law and Social Science, 2019, vol. 15: 1, pp. 335-353

4. Spirkin A.G. Consciousness and self-awareness. Moscow, Political Literature Publishing House, 1972. 304 p.

5. Rubinstein S. L. Fundamentals of General Psychology. Saint-Petersburg, Publishing House Peter. 2008. 713 p.

6. Belinskaya E.P., Tikhomandritskaya O.A. Social personality psychology: Textbook. manual for universities. Moscow, Aspect Press, 2001. 238 p.

7. Andreeva G. M. Social Psychology. Moscow, Aspect Press, 2009. 432 p.

8. James W. D. Psychology. Moscow, Pedagogy, 1991. 368 p.

9. Burns R. Development of self-concept and education. Moscow, 2016. 420 p.

10. Spirkin A.G. Consciousness and self-awareness. Moscow, Political Literature Publishing House, 1972.304 p.

11. Feldstein D.I. The profound changes in modern childhood and the actualization of psychological and pedagogical problems of the development of education due to them [Electronic resource]. Available at: http://psyjournals.ru/ vestnik_psyobr/2011/n4/56243.shtml (accessed 5 September 2019).

12. Boittin M. L. New perspectives from the oldest profession: abuse and the legal consciousness of sex workers in China. Law Soc. Rev., 2013, vol. 47 (2), pp. 245-278. doi: 10.1111 / lasr.12016

13. The Code of the Russian Federation on Administrative Offenses of December 30, 2001. No. 195-FZ (as amended on August 2, 2019).

14. Richman K. D. License to Wed: What Legal Marriage Means to Same-Sex Couples. New York / London: NYU Press. 2014.

15. Harding R. Regulating Sexuality: Legal Consciousness in Lesbian and Gay Lives. London: Routledge. 2011.

16. Blagodatskikh V.G., Kerimov A.A. Education in the structure of the formation of the ecological culture of society. DISCOURSE-PI, 2018, no 18. 1 (30). pp. 40-46

17. Kerimov A., Shutaleva A. Education as a factor in preventing ethnic conflicts in modern Russia // INTED2017: 11th international technology, education and development conference. Chova L. G., Martinez A. L. \& Torres I. C. (Ed.). International Academy of Technology, Education and Development, 2017, pp. 1382-1391.

18. Kerimov A. A. The parliamentary system in modern Russia: peculiarities and problems of implementation. Bulletin of Tomsk State University. Philosophy. Sociology. Political science, 2019, no. 48, pp. 145-153.

19. Rudenkin D., Loginov A. Ideologiya v obshchestve pozdnego moderna: ischeznovenie ili transformatsiya? [Ideology in Late Modern Society: Disappearance or Transformation?]. The Russian Sociological Review, 2018, vol. 17, no. 3, pp. 197-220 (in Russian)

20. Menshikov A.S. Antropologiia bez etnografii: filosofiia voiny M. Shelera i poisk "prirody cheloveka" [Anthropology without Ethnography: M. Scheler's Philosophy of War and the Search for the "Nature of Man"]. Etnograficheskoe obozrenie, 2018, no. 5, pp. 43-58. https://doi.org/10.31857/s086954150001476-3 
Информация об авторе

Муслумов Рустам Рафикович

(Россия, Екатеринбург)

Доцент, кандидат психологических наук, доцент кафедры педагогики и психологии образования

Уральский федеральный университет им. Первого Президента России Б.Н. Ельцина

E-mail:mrr82@yandex.ru

ORCID ID: 0000-0003-1327-1590

\section{Information about the author}

Rustam R. Muslumov

(Russia, Ekaterinburg)

Assistant Professor, PhD in Psychological Sciences,

Associate Professor of Department of Pedagogy and Psychology of Education

Ural Federal University named after First President of Russia B.N. Yeltsin

E-mail: mrr82@yandex.ru

ORCID ID: 0000-0003-1327-1590 